\title{
Could the wavelet synchrony of resting-state EEG discriminate between vegetative state and akinetik mutism in patients with severe brain injury?
}

\section{Introdutction}

Accurate assessment of current functional state of patients in vegetative state or other unconscious states, such as akinetik mutism is very important for correct treatment strategy and rehabilitation activities especially in cases when the difference between those states is not clinically obvious. ${ }^{1-3}$ This is requires searching rigorous methods of functional state assessment.

Brain responses for simple tones ${ }^{4-6}$ and naturalistic stimuli could be used to estimate event-related brain activity ${ }^{7,8}$ whereas the analyses of resting-state EEG could reveal neuronal networking providing a background for responses to stimuli. ${ }^{9}$ Supposedly, the study of restingstate neuronal activity could help to search individual stimuli to bring brain activity to the level where the purposeful activity of patients is possible.

This pilot study is dedicated to revealing features of resting-state wavelet synchrony in unconscious patients with severe brain injury. We suppose that revealed features could help in assessment of a current state and selection of efficient rehabilitation activity.

\section{Methods}

Brain activity of 9 in-patients with severe brain injury (TBI) treated in Burdenko National Medical Research Center of Neurosurgery was analyzed in the study. The experimental protocol was approves by the
Volume 8 Issue 3 - 2018

\author{
Oknina LB,' Zigmantovich AS,' Zaitsev OS, \\ Masherov EL, ${ }^{2}$ Sharova EV' \\ 'Institute of Higher Nervous Activity and Neurophysiology of \\ the RAS, Russia \\ ${ }^{2}$ Burdenko National Medical Research Center of Neurosurgery, \\ Russia
}

Correspondence: Oknina LB, Institute of Higher Nervous Activity and Neurophysiology of the RAS, Russia, Email leliia@yandex.ru

Received: March 29, 2018| Published: June 042018

local Ethics Committee (Burdenko Neurosurgery Institute Research Center of Neurosurgery). Taking into accountthat all patients were in unconscious state the written informed consent was obtained from patients' relatives. Prior the experiment relatives of patients received complete information about the methods and goals of research.

Patients' age varied from 15 to $72(33,8 \pm 18,3$ years). The total of 22 studies was analyzed. Follow up was from 6 months to 8 years. Characteristics of patients, their functional state during the first EEGrecord after TBI and outcome are presented in Table 1.

Table I Characteristics of patients, their functional state during the first EEG-record after TBI and outcome and the features of synchrony mapping in restingstate EEG

\begin{tabular}{|c|c|c|c|c|c|c|c|}
\hline Patient & Gender & $\begin{array}{l}\text { Age } \\
\text { (years) }\end{array}$ & $\begin{array}{l}\text { Follow up } \\
\text { (years) }\end{array}$ & $\begin{array}{l}\text { Functional state } \\
\text { during the first EEG }\end{array}$ & outcome & $\begin{array}{l}\text { Maximal wavelet } \\
\text { synchrony, } \\
\text { hemisphere }\end{array}$ & $\begin{array}{l}\text { Maximal wavelet- } \\
\text { synchrony, area }\end{array}$ \\
\hline 1 & M & 34 & 8 & $\mathrm{AM}$ & Cons.* & d & F-C \\
\hline 2 & $\mathrm{~F}$ & 72 & 5 & VS & VS & $\mathrm{s}$ & C-P \\
\hline 3 & M & 20 & 5 & $\mathrm{AM}$ & $\mathrm{AM}$ & $\mathrm{d}$ & F-C-T \\
\hline 4 & $\mathrm{~F}$ & 63 & 4 & $\mathrm{AM}$ & Cons. & d & F-C-T, P-C \\
\hline 5 & M & 56 & 0,5 & VS & Cons. & $\mathrm{s}$ & F-C, P-C \\
\hline 6 & $\mathrm{~F}$ & 35 & 0,5 & $\mathrm{AM}$ & Cons. & $\mathrm{s}$ & F-C-P \\
\hline 7 & M & 37 & 1,2 & VS & VS/death & $\mathrm{s}$ & F-C \\
\hline 8 & M & 23 & 3 & $\mathrm{AM}$ & Cons. & $\mathrm{s}$ & C-P, O \\
\hline 9 & $\mathrm{~F}$ & 21 & 5 & VS & Cons. & $\mathrm{d}$ & P-T \\
\hline
\end{tabular}

*-consciousness recovery in 7 years after TBI, outcome-death due to cardiac arrest.

M, male; F, female; VS, vegetative state; AM, akinetik mutism; Cons., consciousness recovery; F, frontal; C, central; P, parietal; O, occipital; T, temporal; d, right hemisphere; s, left hemisphere. 
The control group consisted of 30 healthy subjects aged 18 to 59 (mean age $30 \pm 13$ ).${ }^{10}$ Brain activity was recorded on the equipment Neurobotics (Russia) from 32 sites. Vertical and horizontal electrooculograms were recorded from the right supra-orbital margin and outside corner of the eye fissure for monitoring blinking and eye movement and further off-line artifact correction $(>50 \mathrm{mkV})$. EEG was recorded with common ear electrodes. Impedance was less than $5 \mathrm{kOm}$ and the range from 0.1 to $100 \mathrm{~Hz}$, the 16-bit amplifier was used. Discretization was $1024 \mathrm{~Hz}$.

Data analysis. 3 minute EEG without artifacts was used to analyze wavelet synchrony. 30 points were randomly sited onEEG. Wavelet synchrony was calculated in intervals including $800 \mathrm{~ms}$ after the point and averaged. For wavelet synchrony calculation ${ }^{11}$ maternal wavelet-Morlet with parameters $\mathrm{F}_{\mathrm{b}}=1$ and $\mathrm{F}_{\mathrm{c}}=1$ was used. The values of synchrony were calculated for all pairs of sites. Calculation of

A

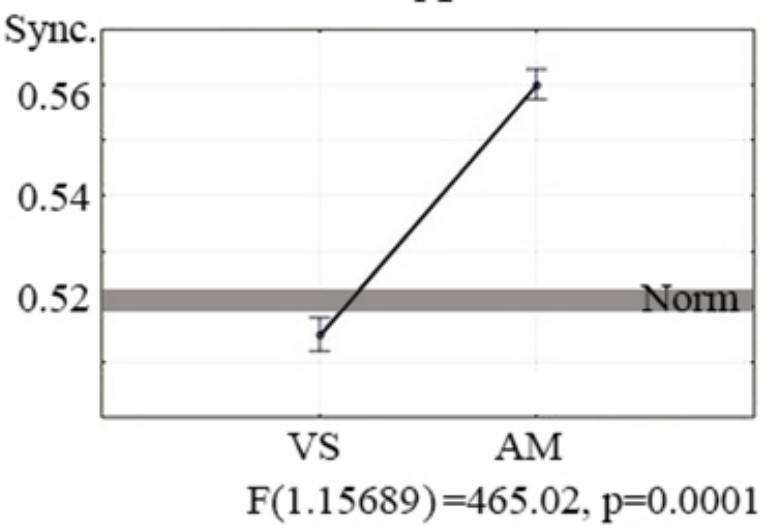

synchrony was made in the range $1-15 \mathrm{~Hz}$. The range was determined by the fact that $1 \mathrm{~Hz}$ filter rejects slow artifacts due to oculogramm and $15 \mathrm{~Hz}$ border allows to exclude from calculation high-frequency miographyoscillations. To calculate a repeated measures effect, the permutation test was used. ${ }^{12}$

\section{Results}

Although wavelet-connectivity detected in unconscious patients varied, it was possible to reveal some features typical for patients in vegetative state and akinetik mutism .

The lesser value of wavelet synchrony was detected in patients with chronic vegetative state in comparison to the norm or patients in mutism. The dependence of resting-state wavelet synchrony from current state and outcome according to variance analysis (ANOVA) is presented in Figure 1.

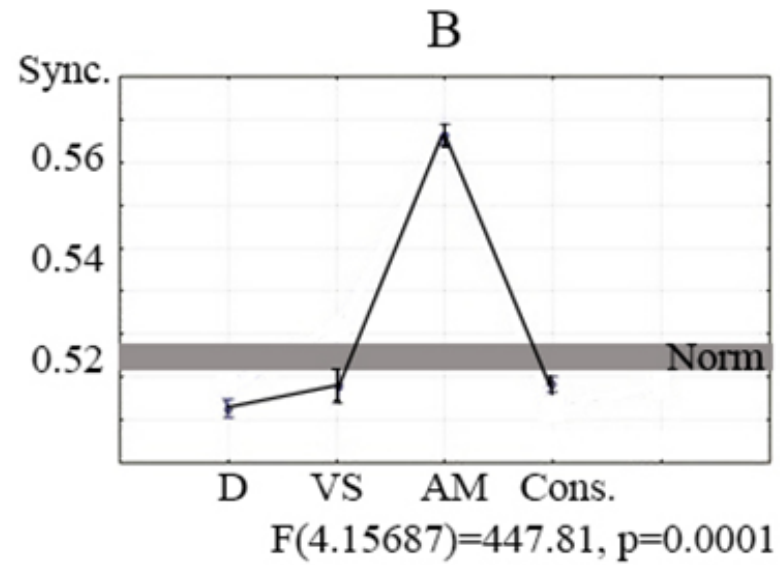

Figure I Dependence of wavelet synchrony from A, current state; B, outcome;VS, vegetative state;AM, akinetik mutism; D, death; Cons., consciousness recovery.

In case of the most favorable outcome of VS, the maximum of wavelet synchrony was mapped in the posterior areas (parietal area), in comparison to cases of VS reversible in a lesser degree, when stronger wavelet synchrony leaned towards the inferior area (frontal and central areas).

\section{Discussion}

The increased value of wavelet synchrony in posterior areas, detected in patients with good recovery could reflect stronger brainstem influence essential for reaching the "right" background activation level that allows passing the threshold needed for involving other structures in activation processes. This correlates with the published data on the functional role of brainstem in processes of consciousness recovery. ${ }^{13}$ It is crucial that similarly increased wavelet synchrony was not detected in patients with chronic vegetative state.

The resting-state wavelet synchrony in patients in mutism has a significantly higher value in comparison to both the norm and vegetative state. Supposedly, the individual stimuli could be selected to decrease the level of activation.

A low level of synchrony is due to be increased up to a certain activation level for stabilization of many chaotically appearing combinations of brain neuronal activity needed to involve patients in voluntary processes.

\section{Study limitation}

Although the features of wavelet synchrony in vegetative state and mutism are distinct enough, the data obtained do not allow us to make a reliable prognosis of consciousness recovery due to the limited number of patients.

\section{Conclusion}

Wavelet synchrony could be used to discriminate between vegetative state and mutism: patients in vegetative state have a lower value of wavelet synchrony in comparison to norm, whereas patients in mutism, a significantly higher.

\section{Acknowledgements}

Study was supported by RAS and RFFI 18-013-00967.

\section{Conflict of interest}

The author declares no cnflict of interest.

\section{References}

1. Childs NL, Mercer WN, Childs HW. Accuracy of diagnosis of persistent vegetative state. Neurology.1993;43(8):1465-1467.

2. Dobrokhotova TA, Potapov AA, Zaitsev OS, et al. Reversible 
postcomatose unconscious states. Zh sotsialnoi i klinicheskoi psihiatrii ( $J$ social and clinical psychiatry). 1996;2:26-36.

3. Giacino JT, Fins JJ, Laureys S, et al. Disorders of consciousness after acquired brain injury: the state of the science. Nat Rev Neurol. 2014;10(2):99-114.

4. Guerit JM, Verougstraete D, Tourtchaninoff M, et al. ERPs obtained with the auditory oddball paradigm in coma and altered states of consciousness: clinical relationships prognostic value and origin of components. Clin Neurophysiol. 1999;110(7):1260.

5. Vanhaudenhuyse A., Laureys S., Perrin F. Cognitive event-related potentials in comatose and post-comatose states. Neurocrit Care. 2008;8(2):262-270.

6. Oknina LB, Sharova EV, Zaitsev OS, et al. Long-latency components (N100, N200 and P300) of acoustic evoked potentials in prediction of mental recovery in severe traumatic brain injury. Zh Vopr Neirokhir Im N N Burdenko. 2011;753:19-30.

7. Signorino M, D'Acunto S, Angeleri F, et al. Eliciting P300 in comatose patients. Lancet. 1995;345(8944):255-256.
8. Signorino M, D'Acunto S, Cercaci S, et al. The P300 in traumatic coma: conditioning of the odd-ball paradigm. J Psychophysiol. 1997;11:59-70.

9. Bai Y, Xia X, Li X. A Review of resting-state electroencephalography analysis in disorders of consciousness. Front Neurol. 2017;8:471.

10. Oknina LB, Kuptsova SV, Romanov AS, et al. Sharova Comparative analysis of changes in short EEG segments during music perception based on event-related synchronization/desynchronization and wavelet synchronicity. Fiziologia cheloveka (Human Physiology). 2012;4:11-18.

11. Romanov AS, Sharova EV, Kuznetsova OA, et al. Possibility of waveletsynchronization methods for estimation of spatial distribution of components of auditory evoked potentials in healthy subjects. Zhurnal vysshei nervnoi deiatelnosti imeni I P Pavlova. 2011;61(1):112.

12. Blair RC,Troendle JF, Beck RW. Control of family wise errors in multiple endpoint assessments via stepwise permutation tests. Stat Med. 1996;15(11):1107-1121.

13. Sharova EV, Novikova EV, Kulikov MA. Compensatory brain reactions in acute damage of brainstem. Moscow: Synteg; 2009. 